\title{
Transmission of African swine fever virus from infected pigs by direct contact and
} aerosol routes

Olesen, Ann Sofie; Lohse, Louise; Boklund, Anette ; Hisham Beshara Halasa, Tariq; Gallardo, Carmina; Pejsak, Zygmunt ; Belsham, Graham; Rasmussen, Thomas Bruun; Bøtner, Anette

Published in:

Veterinary Microbiology

Link to article, DOI:

10.1016/j.vetmic.2017.10.004

Publication date:

2017

Document Version

Peer reviewed version

Link back to DTU Orbit

Citation (APA):

Olesen, A. S., Lohse, L., Boklund, A., Hisham Beshara Halasa, T., Gallardo, C., Pejsak, Z., Belsham, G., Rasmussen, T. B., \& Bøtner, A. (2017). Transmission of African swine fever virus from infected pigs by direct contact and aerosol routes. Veterinary Microbiology, 211, 92-102. https://doi.org/10.1016/j.vetmic.2017.10.004

\section{General rights}

Copyright and moral rights for the publications made accessible in the public portal are retained by the authors and/or other copyright owners and it is a condition of accessing publications that users recognise and abide by the legal requirements associated with these rights.

- Users may download and print one copy of any publication from the public portal for the purpose of private study or research.

- You may not further distribute the material or use it for any profit-making activity or commercial gain

- You may freely distribute the URL identifying the publication in the public portal 


\section{Transmission of African swine fever virus from}

\section{infected pigs by direct contact and aerosol routes}

Ann Sofie Olesen ${ }^{\mathrm{a}}$, Louise Lohse ${ }^{\mathrm{a}}$, Anette Boklund ${ }^{\mathrm{b}}$, Tariq Halasa ${ }^{\mathrm{b}}$, Carmina

Gallardo $^{\mathrm{c}}$, Zygmunt Pejsak ${ }^{\mathrm{d}}$, Graham J. Belsham ${ }^{\mathrm{a}}$, Thomas Bruun Rasmussen ${ }^{\mathrm{a}}$, Anette Bøtner ${ }^{a *}$

${ }^{a}$ DTU National Veterinary Institute, Technical University of Denmark, Lindholm, DK-4771

Kalvehave, Denmark

${ }^{b}$ DTU National Veterinary Institute, Technical University of Denmark, Kemitorv, building 204, DK-2800 Kgs. Lyngby, Denmark

${ }^{c}$ European Union Reference Laboratory (EURL) for African swine fever, INIA-CISA, 28130 Valdeolmos, Madrid, Spain

${ }^{d}$ National Veterinary Research Institute, Department of Swine Diseases, Partyzanrow 57, 24-100 Pulawy, Poland

*Correspondence: Professor Anette Bøtner, Division for Diagnostics and Scientific Advice, DTU National Veterinary Institute, Technical University of Denmark, Lindholm DK-4771 Kalvehave, Denmark. aneb@vet.dtu.dk

Highlights:

- ASFV was transmitted efficiently via direct contact and exposure through air.

- Clinical and pathological findings were typical of ASFV infection.

- Obtained transmission parameters can be used in ASFV spread models. 


\section{ABSTRACT}

In 2014, African swine fever virus (ASFV) was introduced into the Baltic states and Poland. Since then, the disease has continued to spread within these regions, and recently, cases were reported in the Czech Republic and Romania. Currently, there is an increasing risk of ASFV introduction into Western Europe. Hence, there is an urgent need to assess current contingency plans. For this purpose, knowledge of modes-of-transmission and clinical outcome in pigs infected with new European ASFV strains is needed. In the present study, two experiments were conducted in pigs using an isolate of ASFV from Poland (designated here POL/2015/Podlaskie/Lindholm). In both studies, pigs were inoculated intranasally with the virus and contact pigs were exposed to the experimentally infected pigs, either directly (contact within and between pens) or by air. Pigs exposed to the virus by intranasal inoculation, by direct contact to infected animals and by aerosol developed acute disease characterized by viremia, fever and depression. Infectious virus was first detected in blood obtained from the inoculated pigs and then sequentially among the within-pen, between-pen and air-contact pigs. ASFV DNA and occasionally infectious virus was found in nasal-, oral-, and rectal swabs obtained from the pigs, and ASFV DNA was detected in air samples. No anti-ASFV antibodies were detected in sera.

In conclusion, the study shows that the currently circulating strain of ASFV can be efficiently transmitted via direct contact and by aerosols. Also, the results provide quantitative transmission parameters and knowledge of infection stages in pigs infected with this ASFV. 
Keywords: ASF, Poland, virus transmission, air sampling, haemorrhagic disease

\section{Introduction}

African Swine Fever (ASF) is a severe viral haemorrhagic disease affecting swine (Mebus, 1988). The disease is caused by African swine fever virus (ASFV) which is a large, enveloped, DNA virus and the sole member of the genus Asfivirus within the family Asfarviridae (Dixon et al., 2005).

In 2007, ASFV was introduced into Georgia and subsequently into other Transcaucasian countries, the Russian Federation, Ukraine and Belarus (EFSA Panel on Animal Health and Welfare, 2014). In the beginning of 2014, outbreaks of the disease occurred in the Baltic states and Poland, within wild boar and domestic pigs (EFSA Panel on Animal Health and Welfare, 2015). Outbreaks have continued to occur in the Baltic states and Poland, and more recently, in 2017, ASFV has been reported in wild boar in the Czech Republic and in domestic pigs in Romania (http://www.oie.int/wahis_2/public/wahid.php/Diseaseinformation/WI).

The continued circulation of the virus in Eastern Europe means that there is a risk of further spread of ASFV into Western Europe. In European countries, with a large swine production and substantial exports of swine products, it is predicted that ASF outbreaks will have huge economic consequences, especially due to export restrictions (Halasa et al., 2016a; Halasa et al., 2016b). Hence, enforcement of current ASF contingency plans to achieve early detection and eradication of the disease in these countries is of major importance in order to limit these costs (Halasa et al., 2016c). Currently, since no vaccine 
or treatment options are available to prevent the infection (Zakaryan \& Revilla, 2016), the disease can only be controlled by administrative and regulatory measures. The procedures applied in the event of an outbreak are based on classical disease control strategies (EFSA Panel on Animal Health and Welfare, 2014; CEC, 2002; Gallardo et al., 2015). These include epidemiological investigations, tracing of pigs, stamping out on infected holdings, surveillance and strict movement control (European Commission Working Document, 2013). In order to choose the most effective control strategies, modelling of the epidemiological and economic consequences of an outbreak can be a valuable tool, and recently such analyses of within-herd and between-herd ASFV transmission have been reported (Halasa et al., 2016a; Halasa et al., 2016b). However, in order for these models to reflect the actual conditions that may occur in an outbreak situation, accurate quantitative parameters concerning the nature of ASFV transmission from domestic pigs infected with the currently circulating European ASFV strains are necessary. Also, knowledge of the clinical and pathological aspects of the infection by these strains is important to facilitate early detection of ASFV by farmers, veterinary practitioners and the authorities. In the present study, we have conducted two experiments in pigs with an ASFV isolate obtained from an infected wild boar in Poland in February 2015, this virus is designated here as POL/2015/Podlaskie/Lindholm. Transmission of the virus via direct contact between experimentally infected pigs and susceptible, within-pen- and between-pen contact pigs was investigated. In addition, potential aerosol transmission over a short distance, between pigs within separated pens was analyzed. Previously, transmission studies in pigs using ASFVs from the Georgian incursion of the disease have investigated direct-contact transmission (Guinat et al., 2014; Gallardo et al., 2017), but airborne transmission have only been clearly demonstrated once - using an African isolate of the 
virus (Wilkinson \& Donaldson, 1977). To our knowledge, this is the first study to investigate transmission between pigs via air using a recent European ASFV.

\section{Materials and methods}

\subsection{Animals}

Twenty two pigs, eight to nine weeks of age, $18-25 \mathrm{~kg}$, were included in each of the two studies. The 44 pigs were obtained from a conventional Danish swine herd (Landrace $\mathrm{x}$ Yorkshire x Duroc hybrids) with specific pathogen free (SPF) status. This means freedom from atrophic rhinitis, enzootic pneumoniae, porcine reproductive and respiratory syndrome, swine dysentery and most serotypes of Actinobacillus pleuropneumoniae. On arrival at the research facility, one week before the start of the experiment, all pigs were found to be healthy by veterinary inspection. The pigs were fed a commercial diet for weaned pigs once a day, and water was provided ad libitum. Straw was used for bedding. Animal care and maintenance, experimental procedures and euthanasia were conducted in accordance with Danish and EU legislation on animal experimentation (Consolidation Act 474 15/05/2014 and EU Directive 2010/63/EU) and with the approval from the Danish Animal Experimentation Inspectorate (license number 2015-15-0201-00606).

\subsection{Challenge virus}

Spleen material from a dead wild boar in Podlaskie voivodeship (province), Poland, collected in February 2015, was obtained via the EU Reference Laboratory (EURL) for ASF (Valdeolmos, Spain). At the EURL, the sample (designated as Pol14/WB-17397\#13) was found positive for ASFV by the UPL real-time polymerase chain reaction (PCR) (Fernández-Pinero et al., 2013) and after one passage in porcine blood monocytes (PBM) 
(Carrascosa et al., 2011) showing the characteristic haemadsorbing pattern (data not shown).

For the experimental infections, virus was isolated from the spleen material (as described below) in porcine pulmonary alveolar macrophages (PPAM). These cells were obtained as described by Bøtner et al. (1994), and resuspended in Eagle’s Minimum Essential Medium (EMEM) supplemented with streptomycin (Sigma-Aldrich), neomycin (Sigma-Aldrich) and $5 \%$ fetal calf serum (suppl. EMEM) to a final concentration of $2 \times 10^{6}$ cells $/ \mathrm{mL}$. For isolation of the virus, Nunc ${ }^{\mathrm{TM}}$ cell culture flasks (Thermo Fisher Scientific), containing $10 \mathrm{~mL}$ of the cell suspension, were inoculated with $200 \mu \mathrm{L}$ of a clarified $10 \%$ spleen suspension. After three days incubation at $37^{\circ} \mathrm{C}$, in an atmosphere with $5 \% \mathrm{CO}_{2}$, the first passage virus was harvested by freezing and thawing. For the second passage, $200 \mu \mathrm{L}$ of this virus harvest was added to $10 \mathrm{~mL}$ fresh PPAM, then incubated and harvested as described for the first passage.

The titre of the second passage was determined by end-point titration in PPAM. Following three days incubation (as above), virus infected cells were identified following fixation and staining of the cells using an immunoperioxidase monolayer assay (IPMA) as described for the detection of PRRSV (Bøtner et al., 1994). The cells were stained using ASFV antibody positive swine serum, protein A-conjugated horse-radish peroxidase (Sigma-Aldrich) and hydrogen peroxide and the infected (red-stained) cells were counted using a light microscope. The virus titre (as $\mathrm{TCID}_{50} / \mathrm{mL}$ ) was calculated using the method described by Reed and Muench (1938).

For inoculation of pigs, the second passage virus was diluted in suppl. EMEM to $4 \log _{10}$ TCID 50 per $2 \mathrm{~mL}$. At the time of inoculation, back titration of the inoculum was carried out in PPAM to confirm the administered dose. 


\subsection{Study design}

Upon arrival at the research facility, pigs were randomly allocated into two separate high containment stable units (BSL3 animal isolation facilities), termed unit $I$ and unit $I I$ (Fig. 1). Inside unit $I$, the pigs were divided into the following groups; 1) inoculated pigs, 2) within-pen contact pigs, 3) between-pen contact pigs, and 4) air-contact pigs. Inside unit II, pigs were kept in one group as mock-inoculated control pigs. In study $a, 16$ pigs (pigs 1-16 in groups $1 a-4 a$ ) were allocated to unit $I$ and six pigs (pigs 17-22 in group 5a) to unit $I I$. In study $b, 18$ pigs (pigs 23-40 in groups $1 b-4 b$ ) were allocated to unit $I$ and four pigs (pigs 41-44 in group $5 b$ ) to unit $I I$ (Fig. 1). Unit $I$ had a room volume of $155 \mathrm{~m}^{3}$ and the air within the room was changed 5-10 times/h. Air was recirculated, following HEPA filtration, into the room above pens 1 and 2. The air exit was located adjacent to pen 3 (Fig. 1). Unit $I$ had an average temperature of $20.6^{\circ} \mathrm{C}\left( \pm 0.4^{\circ} \mathrm{C}\right)$ and a relative humidity of $44 \%$ $( \pm 4 \%)$.

Following an acclimatization period of one week, the four pigs in groups $1 a$ (pigs 1-4) and $1 b$ (pigs 23-26) were inoculated intranasally (I.N.) with $2 \mathrm{~mL}$ virus suspension containing $4 \log _{10}$ TCID $_{50}$. The control pigs in group $5 a$ and group $5 b$ were mock-inoculated I.N. with 2 mL suppl. EMEM.

The day after inoculation of groups $1 a$ and $1 b$, i.e. post infection day (PID) 1 , the pigs from group $2 a$ (pigs 5-8) and $2 b$ (pigs 27-30) were moved from pen 4 into pen 1 to serve as within-pen contacts. From PID 0, group $3 a$ (pigs 9-12) and $3 b$ (pigs 31-34) were housed in pen 2 , adjacent to pen 1 , and served as between-pen contacts. These pigs were allowed nose-contact to the pigs in pen 1 between bars dividing the two pens. Groups $4 a$ (pigs 1316) and $4 b$ (pigs 35-40) in pen 3 were separated from pens 1 and 2 by a corridor (ca. $1 \mathrm{~m}$ wide). Pigs in pen 3 were not allowed any direct contact to pigs in pens 1 and 2 and thus 
served as potential contacts for virus transmission via air. In order to avoid indirect virus transmission via equipment and/or personnel to groups $4 a$ and $4 b$, separate equipment was used for these pigs. Also, feeding, caretaking and experimental procedures were performed in these groups before handling the groups in pens 1 and 2.

\subsection{Clinical examination and necropsy}

Clinical scores, including rectal temperatures, were recorded from individual pigs on each day. A total clinical score was calculated per day based on a system slightly modified from that described by Pietschmann et al. (2015). The total clinical scores were calculated as the summation of scores given in ten categories (Table 1) allowing a maximum total clinical score of 42 . The presence of clinical signs was defined as a clinical score above 3 . This threshold was chosen based on the clinical scores obtained in the control groups. The pigs were euthanized through intravascular injection of Pentobarbital following deep anesthesia. At necropsy, body condition and macroscopic findings in skin, organs and body cavities were evaluated and described.

\subsection{Sampling}

\subsubsection{Sampling from the pigs}

In study $a$, unstabilized blood, EDTA-stabilized blood (EDTA blood) and oral-, nasal-, and rectal swabs were collected prior to inoculation (PID 0) and on PID 1, 2, 3, 4, 7, 9 and 11 from group $1 a$. Groups $2 a-5 a$ were sampled on PID $0,3,4,5,6,7,9,11$ and 14 . In study $b$, sampling between the different groups was modified based on the prior results from study $a$. Thus, unstabilized blood, EDTA blood and oral-, nasal-, and rectal swabs were collected on PID $0,2,3,4,5,7,8$ and 9 from group $1 b$. Groups $2 b$ and $3 b$ were sampled on PID $0,5,6,7,8,9,10,11,14$ and 15 , group $4 b$ was sampled on PID $0,5,6,8,9,10,11$, 12, 14 and 15, and group $5 b$ was sampled on PID 0, 7 and 14. In addition, in both studies, 
blood samples were collected from all pigs and nasal-, oral-, plus rectal swabs were collected from most pigs at euthanasia.

Swabs were collected in $1 \mathrm{~mL} 0.85 \% \mathrm{NaCl}$ (study $a$ ) or EMEM supplemented with streptomycin, neomycin and $2 \%$ fetal calf serum (study $b$ ), then frozen at $-80^{\circ} \mathrm{C}$ until further processing and analysis. Serum and EDTA blood samples were frozen at $-80^{\circ} \mathrm{C}$ until analysis.

\subsubsection{Air sampling}

Air samples were collected on each day from PID 0 to PID 11 in study $a$ and from PID 0 to PID 18 in study $b$ using a hand-held AeroCollect (an electrostatic air sampler produced by FORCE Technology) (Jensen et al., 2005). In study $a$, each sample was collected over a period of 5 min., sampling approximately $1 \mathrm{~L}$ of air per sample. Air was sampled $1 \mathrm{~m}$ above the pigs in pens 1 and 3. In these same pens, air samples were collected just above the pen floor. In addition, prior to inoculation and on PID 2, 5, 8 and 11 air samples were collected from the corridor between pens 1 and 3 in unit $I$ and from unit $I I$ (Fig. 1). Additionally, samples were collected from approximately 1-2 cm from the snout of diseased pigs (respiratory air). In study $b$, one sample was collected over a period of $5 \mathrm{~min}$. while another was collected over a period of 60 min., sampling approximately $1 \mathrm{~L}$ or $12 \mathrm{~L}$ of air per sample, respectively. Air was collected $1 \mathrm{~m}$ above the pigs in pens 1, 2 and 3 . Every third day, air samples were collected from the pen housing the mock-inoculated pigs in unit II. Cartridges from the air samplers were frozen at $-20^{\circ} \mathrm{C}$ until further processing.

\subsection{Pre-processing of samples}

Swab samples were thawed, vortexed for approximately $10 \mathrm{sec}$. and centrifuged.

Cartridges from the air sampler were thawed, and $50 \mu \mathrm{L}$ nuclease free water was flushed 
through each one 3-4 times in order to elute the collected particles into the fluid which was then stored at $-80^{\circ} \mathrm{C}$ until further analysis.

2.7. ASFV DNA detection by quantitative real-time polymerase chain reaction ( $q P C R)$ DNA was purified from EDTA blood, sera, nasal-, oral-, and rectal swabs using a MagNA Pure 96 system (Roche) with the DNA/Viral NA S.V. 2.0 and Viral NA Plasma extern lysis S.V. 3.1 protocol.

Extracted DNA and the samples obtained from the air-samplers were tested for the presence of ASFV DNA by qPCR using the Mx3005P qPCR system (Agilent Technologies) essentially as described by Tignon et al. (2011). Absolute quantification was used to determine the number of genome copies by reference to a standard curve based on a 10-fold dilution series of the pVP72 plasmid (King et al., 2003). A positive result in qPCR was determined by identification of the threshold cycle value (Cq), at which FAM dye emission appeared above background within 40 cycles. For nasal-, oral-, and rectal swab samples, consistent detection of $\mathrm{Cq}$ values $<35$ was interpreted as an indication of virus excretion. Cq values $>35$ and/or intermittent detection was interpreted as the presence of viral DNA being obtained from the environment.

\subsection{Virus detection by virus isolation}

Infectious ASFV in serum and swab sample filtrates (filtered using $0.45 \mu \mathrm{m}$ Minisart Syringe filters, Sartorius Stedim Biotech) was detected by end-point titration in PPAM. Serum was used for virus isolation, as less background staining was observed in the low dilutions, when using sera compared to EDTA. Hence, the highest sensitivity for detecting infectious virus was obtained using serum.

For the swab samples, amphotericin $(0.85 \mu \mathrm{g} / \mathrm{mL})$ (Sigma-Aldrich) and benzylpenicillin (1000 UI/mL) (Panpharma) were added to the cell suspensions. The cells were stained for 
the presence of virus, as described above, and the ASFV titres were calculated as $\mathrm{TCID}_{50} / \mathrm{mL}$.

Sera and swab samples found negative in the first passage were passaged once more in PPAM.

\subsection{Antibody detection}

Sera obtained at euthanasia were tested for the presence of anti-ASFV antibodies using an Ingezim PPA Compac ELISA (®INGENASA-INGEZIM PPA COMPAC K3

INGENASA) that detects antibodies directed against the VP72 protein. The test was performed according to the manufacturer's instructions.

\subsection{Statistical analyses}

The average duration of the time until onset of clinical signs (the incubation period in the inoculated pigs) was calculated as the average duration between PID 0 and the appearance of clinical signs (clinical score above 3 ). The average duration of time until onset of infectiousness (the latent period in the inoculated pigs) was calculated as the average time between PID 0 and the first detection of virus/viral DNA in the different sample types. For swab samples, first detection was defined as the first consistent detection of $\mathrm{Cq}$ values $<$ 35 .

For all groups, the different time periods were calculated as mean \pm standard deviation. The average duration of each of the different time periods was compared between groups using a one-way analysis of variance (one-way ANOVA) and post-hoc analysis (Tukey's test), and between individual groups using an unpaired, two-tailed Student's T-test in GraphPad Prism (GraphPad Software).

\section{Results}




\subsection{Virus isolation}

ASFV was isolated from the spleen of a wild boar from Poland in 2015 using PPAM. After a second passage the virus titre was $5 \log _{10}$ TCID $50 / \mathrm{mL}$. This virus isolate, as used for the subsequent experiments, was designated POL/2015/Podlaskie/Lindholm.

\subsection{Course of infection}

\subsubsection{Inoculated pigs}

Pigs 1-4 (group 1a) were inoculated intranasally on PID 0 with a virus suspension that was shown to contain $4.1 \log _{10} \mathrm{TCID}_{50} / 2 \mathrm{~mL}$. Following inoculation, pig 4 displayed slight depression and hyperemic skin on PID 4. Fever (temperature above $40^{\circ} \mathrm{C}$ ), severe depression, anorexia and weakness was observed on PID 5, when the pig was euthanized due to severe rectal bleeding. Two other pigs in this group, pigs 1 and 3, appeared depressed starting from PID 4 and 5, and fever, reduced food intake developing into anorexia, hyperemic skin and slight ataxia were observed in these pigs prior to euthanasia on PID 6 (Fig. 2A). One pig in group 1a, pig 2, showed a delayed course of infection with fever starting from PID 9. This pig appeared depressed and would not eat prior to euthanasia on PID 11.

Pigs 23-26 (group $1 b$ ) were inoculated intranasally on PID 0 with a virus suspension containing $4.6 \log _{10} \mathrm{TCID}_{50} / 2 \mathrm{~mL}$. Following inoculation, fever was observed in pigs 23 , 25 and 26 starting from PID 5 and 6. On subsequent days, a further increase in temperature, along with depression, reduced food intake or anorexia were observed in these pigs. The pigs were euthanized on PID 6, 7 and 8, respectively (Fig. 2A). Prior to euthanasia, incoordination and diarrhea were observed in pig 23, and pig 25 had rectal bleeding. The last pig in group $1 b$, pig 24 , had a prolonged time course of infection with fever from PID 8, and on the following days depression and reduced food intake were 
observed. Vomiting was observed on PID 11, and later the same day the pig was found dead.

In the inoculated pigs, clinical signs were accompanied by the detection of viral DNA in EDTA blood and sera (Fig. 2B and supplementary data (sera)) together with the detection of infectious virus (viremia) in sera (see supplementary data (sera)). Nasal-, oral-, and rectal swabs obtained from most inoculated pigs were positive by qPCR prior to, or at euthanasia, and the first detection of viral DNA in swabs often coincided with the first detection of viral DNA in EDTA blood samples and the appearance of clinical signs (Fig. 2). However, prior to the detection of samples with levels of viral DNA indicating virus excretion (Fig. 2B), some oral- and rectal swabs obtained from pigs 2 and 24, in particular, were found to contain low levels of viral DNA (Fig. 2B) on several days prior to the presence of clinical signs and viremia. This was, as previously mentioned, interpreted as being indicative of ASFV DNA obtained from the environment, rather than due to virus excretion from these pigs. Infectious virus was isolated from rectal swab samples containing blood collected at euthanasia from pigs 4, 24 and 25 with titres ranging from 2.8-3 $\log _{10}$ TCID $50 / \mathrm{mL}$ swab filtrate. Furthermore, infectious virus was isolated from nasal swabs obtained from pigs 23-26 prior to, or at euthanasia, with titres ranging from 1.6-4.8 $\log _{10} \mathrm{TCID}_{50} / \mathrm{mL}$ swab filtrate. No infectious virus was isolated from oral swabs collected from the inoculated pigs.

\subsubsection{Direct contact pigs}

In group $2 a$, pig 7 was euthanized on PID 6 due to general exhaustion and watery diarrhea. This pig was not viremic and no viral DNA was detected in blood samples obtained at euthanasia (Fig. 3B and supplementary data (sera)). Fever occurred in the remaining within-pen contact pigs in group $2 a$ and the between-pen contact pigs in group $3 a$ from 
between PID 8 to 10, and in all pigs an increase in rectal temperature was observed until euthanasia on PID 11 or 12 (Fig. 3A and Fig. 4A). Clinical findings prior to euthanasia included depression, anorexia, ataxia, inability to stand/or remain standing and hyperemic skin. Furthermore, pig 6 developed severe nasal bleeding and in pigs 10 and 11 convulsions were observed.

In pigs 27-30 (group $2 b$ ) and pigs 31 and 33 (group $3 b$ ) fever was first observed from PID 11 to 13 . Clinical findings included depression, reduced food intake or anorexia and hyperemic skin. These six pigs were euthanized on PID 12, 13 and 14 (Fig. 3A and Fig. 4A). At euthanasia, severe rectal bleeding was observed in pigs 30 and 31. Pig 34, had fever from PID 15, and on PID 16 severe lameness, most likely due to an external injury that was not related to the infection, was seen in this pig, and it was euthanized for animal welfare reasons. Pig 32, which appeared clinically healthy, but found to be viremic, was euthanized on the same day, as it was the last pig left in pen 2.

In blood samples obtained from the direct contact pigs, except for pig 7 (as above), viral DNA and infectious virus could be detected in EDTA blood and sera, respectively, collected prior to, or following, euthanasia (Fig. 3B, Fig. 4B and supplementary data (sera)). Nasal-, oral-, and rectal swabs were positive by qPCR prior to euthanasia, and in many of the pigs, viral DNA could be detected in swabs prior to the detection of viral DNA in blood samples and prior to the appearance of clinical signs (Fig. 3 and Fig. 4). Prior to the detection of clinical signs and viral DNA in blood, viral DNA in the different swab samples was often detected intermittently and levels were low (Fig. 3B and Fig. 4B). Infectious virus was isolated from rectal swab samples collected post euthanasia from pigs 27, 28, 30 and 31 (samples from pigs 30 and 31 contained visible blood). Virus titres ranged from 1.6-3.8 $\log _{10} \mathrm{TCID}_{50} / \mathrm{mL}$ swab filtrate and were highest, when blood was 
present. From nasal swabs, obtained at euthanasia from pigs 6 (blood present), 8, 28, 29, 30, 31 and 33, infectious virus was detected with titres ranging from 1.8-2.8 $\log _{10}$ $\mathrm{TCID}_{50} / \mathrm{mL}$ swab filtrate. No infectious virus was isolated from oral swabs collected from the direct contact pigs.

\subsubsection{Air-contact pigs}

Among the air-contact pigs in group $4 a$, fever and depression were observed from PID 11 and PID 12 in pigs 13,14 and 15. Other clinical signs were similar to those observed in the direct-contact pigs in groups $2 a$ and $3 a$ but were delayed by 3-5 days. A sudden drop in rectal temperature was measured in pig 14 prior to euthanasia at PID 12. In pig 13, facial convulsions (lasting approximately 30 seconds in total) were observed in the morning on PID 13. No convulsions were observed in the afternoon or evening the same day. The pig was found dead in the pen on PID 14, when the two remaining animals, pig 15 and pig 16, were euthanized (Fig. 5A). At euthanasia, pig 15 had developed mild rectal bleeding. Pig 16 did not show significant clinical signs besides mild diarrhea and a slight increase in body temperature prior to euthanasia. Pig 16 was euthanized despite the lack of clinical signs, as it was the last pig left in stable unit $I$.

In group 4b, fever and reduced feed intake was observed in pigs 36 and 37 on PID 14. Rectal bleeding occurred in pig 37 on PID 15, when it was euthanized. On PID 16, pig 36 was found in a recumbent position, and a drop in body temperature was measured prior to euthanasia of this pig. The four remaining pigs in group $4 b$ were euthanized on PID 17 or 18 due to the termination of the experiment. One remaining pig in group $4 b$, pig 35 , had a fever and was slightly depressed at euthanasia on PID 17. Pigs 38-40 were clinically healthy, when they were euthanized on PID 17 and 18, respectively (Fig. 5A). 
The clinical findings in the air-contact pigs were accompanied by the detection of viral DNA and infectious virus in blood samples obtained from these pigs (Fig. 5B and supplementary data (sera)). Despite the lack of clinical signs in pigs 39 and 40, viral DNA and infectious virus were detected in EDTA blood and sera, respectively, obtained from these pigs at euthanasia, while no viral DNA or infectious virus was detected in blood samples obtained from pigs 16 and 38.

In the air-contact pigs, nasal-, oral-, and rectal swabs obtained from most pigs were positive by qPCR prior to euthanasia, and in some pigs low levels of viral DNA could be detected, sometimes intermittently, in swab samples for some days prior to the detection of viral DNA in blood samples and/or the presence of clinical signs (Fig. 5). Infectious virus was isolated from blood-containing rectal swab samples collected following euthanasia from pigs 15 and 37 . The sample obtained from pig 15 had a titre of $3.0 \log _{10}$ TCID $50 / \mathrm{mL}$ swab filtrate. The sample obtained from pig 37 was only found positive for infectious virus following two passages in cell culture, i.e. only a very low level of virus was present. Infectious virus was obtained from the nasal swabs collected post euthanasia from pigs 13 and 39 and had titres ranging from 1.6-3.8 $\log _{10}$ TCID $50 / \mathrm{mL}$ swab filtrate. On three subsequent days, prior to euthanasia, infectious virus was isolated from nasal swabs collected from pig 36 with virus titres ranging from 1.8-3.6 $\log _{10} \mathrm{TCID}_{50} / \mathrm{mL}$ filtrate. No infectious virus was isolated from oral swabs collected from the air-contact pigs.

\subsubsection{Control pigs}

No clinical signs of infection were observed, and no ASFV DNA was detected in blood samples or in nasal-, oral- or rectal swabs obtained from the control pigs throughout the course of these studies.

\subsection{Transmission parameters}


The average time until onset of clinical signs (CS above 3 ) and the average time until onset of infectiousness for the eight groups of pigs are shown in Tables 2 (study a) and 3 (study $b$ ). On average, the inoculated pigs in group $1 a$ and $1 b$ started showing clinical signs on PID $6 \pm 2.7$ and on PID $6.3 \pm 1.3$, respectively. These pigs were followed sequentially by the pigs in groups $2 a, 3 a$ and $4 a$ on PID $8.3 \pm 1.5,10.0 \pm 0.8$ and $12.8 \pm 1.0$ and the pigs in groups $2 b, 3 b$ and $4 b$ on PID $12.3 \pm 1.0,13.3 \pm 1.5$ and $15.0 \pm 1.7$, respectively. The time until onset of clinical signs was not significantly different $(\mathrm{P}>0.05)$ from the time until detection of infectious virus or viral DNA in sera, respectively. EDTA blood samples were usually positive by qPCR at least one day prior to the corresponding sera, and the serum levels of viral DNA were consistently lower compared to those seen in EDTA blood (Fig. 2B-5B and supplementary data (sera)).

\subsection{Pathological findings}

At postmortem examination, enlarged, haemorrhagic and oedematous lymph nodes were observed, especially, among the gastric and mediastinal lymph nodes. In some pigs, such lesions were observed in most of the intrinsic lymph nodes. Other lesions included darkcolouring and oedema of the tonsils, sometimes accompanied by pustules or haemorrhages, haemorrhagic splenomegali, few petechial bleedings in the renal cortex, ecchymoses in the bladder wall (in one pig) and bleeding from the most caudal part of the colonic mucosa. Hydroabdomen and hydropericardium with straw to cognac coloured fluid was observed in some pigs. Sometimes, continued bleeding occurred during necropsy, and occasionally large amounts of blood were found in the abdominal cavity. In other pigs, few pathomorphological changes were observed.

\subsection{Anti-ASFV antibody detection}


No anti-ASFV (VP72) antibodies were detected by ELISA in serum samples obtained at euthanasia from any of the pigs (data not shown).

\subsection{Virus detection in the air samples}

In study $a$, ASFV DNA was detected in daily collected air samples collected, from PID 5 until PID 11 in pen 1, and from PID 7 and PID 8 in pen 3 (Fig. 6A). No viral DNA was detected in the air samples collected in the corridor between the pens. In study $b$, ASFV DNA was detected in the air on PID 8, PID 10, PID 13 and PID 14 in pen 1. Viral DNA was detected in samples collected in pen 2 on PID 13, PID 14, PID 16 and PID 17, and in samples collected in pen 3 on PID 10 and each day from PID 14 until PID 18 (Fig. 6B). Detection of viral DNA in air samples and viral loads in these samples are shown along with the clinical scores in the different groups in Fig. 6.

\section{Discussion}

In these studies, acute disease and viremia occurred in pigs exposed to a recent strain of ASFV from Poland (POL/2015/Podlaskie/Lindholm) via intranasal inoculation, via direct contact within- and between pens, and through the air. Clinical findings and pathological outcomes were in accordance with earlier infection studies described using ASFVs circulating in the Transcaucasian and Eastern European regions (Guinat et al., 2014; Pietschmann et al., 2015; Gallardo et al., 2017). Furthermore, the clinical results are in accordance with observations from field outbreaks in affected areas (EFSA Panel on Animal Health and Welfare, 2014; Gogin et al., 2013).

Within all groups, some pigs succumbed to the infection earlier than others. Hence, some pigs survived for several days with fever and depression, while others died or reached the pre-determined humane end points more quickly. A delayed course of infection in some 
inoculated pigs has been reported previously in infection studies with Caucasian and European ASFV isolates (Guinat et al., 2014; Gallardo et al., 2017). In our studies, pig 2 (study $a$ ) showed a course of infection similar to that observed in the within-pen contact pigs. This could suggest, that this pig was not infected by the inoculation, but might have been infected via direct-contact to the other inoculated pigs. In study $b$, pig 24 became infected prior to the within-pen contact pigs. This suggests, that pig 24 was successfully infected at inoculation, but had a prolonged time course of infection. Variation in the course of infection within the different pig groups could be due to differences in the individual pig susceptibility to the virus infection, and studies aimed at investigating individual susceptibility and immune responses to the virus infection in pigs of different gender, age, etc. could be warranted. Furthermore, differences in disease progression may be due to different transmission efficiencies within the different contact groups, as previously described (Guinat et al., 2014).

In our studies, the incubation periods observed following intranasal inoculation were $6 \pm 2.7$ days (study $a$ ) and $6.3 \pm 1.3$ days (study $b$ ), and are in accordance with incubation periods reported previously for ASFV following oro-intranasal inoculation (Mebus, 1988). In earlier studies using ASFVs from Georgia and Lithuania, an incubation period of 4-5 days was reported following intramuscular injection (Guinat et al., 2014; Gallardo et al., 2017). This difference may be explained by different routes of inoculation, or by the inclusion of the two inoculated pigs showing a delayed course of infection in the present study. Without the inclusion of these two pigs, incubation periods were $4.7 \pm 0.6$ days (study $a$ ) and $5.7 \pm 0.6$ days (study $b$ ).

The time until detection of clinical signs in the direct-contact pigs in groups $2 a$ and $3 a$, corresponds well to that reported by Guinat et al. (2014), in which within-pen contact pigs 
started showing clinical signs at approximately 10 days post inoculation of the pigs in group 1a. In groups $2 a$ and $3 a$, clinical signs were observed 3-5 days following exposure to infectious blood excreted from one inoculated pig (pig 4) with severe rectal bleeding on PID 5. This suggests, that oronasal exposure to high amounts of virus excreted from this pig could be the cause of infection in these groups. Supporting this, viral DNA was detected intermittently in oral and nasal swabs from pigs in these groups on, or after, PID 5 , most likely initially caused by virus obtained from the environment. However, virus shedding due to primary replication in the tonsil and retropharyngeal lymph nodes prior to the onset of viremia cannot be ruled out, as discussed by Pietschmann et al. (2015). In prior ASFV infection studies, direct contact to bloody discharges from infected pigs has also been linked to transmission (Gabriel et al., 2011; Pietschmann et al., 2015), and results from this study are consistent with the view that blood is a very potent source of infection, as virus titres in blood sampled collected late in the course of infection were often higher than those observed in nasal and rectal swabs. Also, based on our findings, it seems as if the excretion of infectious virus via nasal-oral- and rectal swabs is often intermittently or absent (e.g. in oral swabs), and does not contribute to a high level of infectious virus in the environment. It should, however, be kept in mind that several factors including low amount of virus in some swab samples and pre-processing (filtration) could effect the detection of low levels of infectious virus by virus isolation.

The direct-contact pigs in study $b$, groups $2 b$ and $3 b$, started showing clinical signs 3-4 days later than the direct-contact pigs in study $a$, between 6-10 days following the first detection of clinical signs in inoculated pigs in group $1 b$ on PID 5. Starting from PID 5 and PID 7, low levels of ASFV DNA were detected, sometimes intermittently, in nasal-, oraland rectal swabs obtained from groups $2 b$ and $3 b$, respectively, indicating that, as in study 
$a$, the virus excreted from diseased inoculated pigs could be transmitted to these pigs from PID 5. In study $b$, large amounts of infectious blood were not excreted to the environment from the inoculated pigs. Therefore, it seems as if the course of infection in direct-contact pigs in this study could be more prolonged due to this lack of a very potent source of infection i.e. infectious blood. Instead, transmission must have relied on secretions or excretions from the inoculated pigs.

In air samples collected during study $a$, the detection of ASFV DNA from PID 5 in pen 1 is coincident with the excretion of large amounts of blood from pig 4 and the presence of clinical signs in most of the inoculated pigs. In group $4 a$, low levels of viral DNA were detected in nasal swabs obtained from some air-contact pigs at PID 6, and the following day viral DNA was detected in the air samples from pen 3. Disease was, however, not apparent in these pigs until 5-6 days following this detection. These findings suggest, that infectious virus was transmitted by aerosol from the pigs in pen 1 at around PID 6-7 and resulted in clinical disease in the pigs in group $4 a$ some 5-7 days later. In study $b$, viral DNA could not be detected in air samples from pen 1 prior to PID 8, indicating, that large amounts of virus were not excreted from the pigs in group $1 b$. The later detection of viral DNA in air samples from pens 1, 2 and 3 corresponds well to the course of infection in groups $2 b, 3 b$ and $4 b$, respectively. However, the detection of viral DNA on PID 10 in air samples from pen 3, approximately 5 days before detection of clinical signs in air-contact pigs in this pen, indicates that virus was transmitted via the air to these pigs. Furthermore, the assumption of aerosol transmission over short distances was supported by the finding of similar levels of viral DNA in samples from above the pen floor and from $1 \mathrm{~m}$ above the pigs in study $a$. In this study, we did not measure infectious virus in air, but previously it has been shown that infectious virus can be excreted to the air from pigs during acute 
ASFV infection (de Carvalho Ferreira et al., 2013). These findings along with the successful infection of pigs via air in our studies and in a study by Wilkinson \& Donaldson (1977) confirm that infectious virus shed from diseased pigs can be transmitted via air over short distances. Taken together, these findings show, that transmission via air could be an important mode of ASFV transmission within farms.

Within all groups, the apparent latency period/time until onset of infectiousness in EDTA blood was shorter when compared to the corresponding serum samples. The earlier detection in EDTA blood compared to serum is presumably due to an association between the virus and the cellular fraction of the blood, especially strong evidence for an erythrocyte-ASFV association has been shown (Wardley \& Wilkinson, 1977). This implicates that the qPCR assay has a higher sensitivity towards whole blood, in which viral DNA loads are higher.

These studies emphasize the highly contagious nature of an ASFV isolate from Poland in experimental settings. However, more moderate contagiosity and less rapid transmission have been shown in other experimental studies (Pietschmann et al., 2015) and under field conditions in some European regions (Ol̦ševskis et al., 2016; Woźniakowski et al., 2016). Higher contagiosity and rapid transmission may be due to differences in inoculation dose, excretion patterns etc. In our studies, the same inoculation dose was used in both experiments, but transmission to contact pigs was more rapid in study $a$, presumably caused by differences in excretion patterns (e.g. severe rectal bleeding) in group $1 a$ compared to group $1 b$. Hence, the course of infection in individual pigs, which can be affected by several factors, can determine the speed of the transmission under both experimental and field conditions. 
In conclusion, these studies show, that the ASFV strain (POL/2015/Podlaskie/Lindholm) obtained from a wild boar case occurring in 2015 can be efficiently transmitted to naïve pigs via direct contact and through air. Also, the results provide quantitative transmission parameters and knowledge of infection stages in pigs infected with this strain of ASFV. The estimated transmission parameters obtained from this study should, however, be considered carefully, as several factors of the study design, including sampling intervals and euthanasia of the pigs, can affect the estimation of some transmission parameters. Hence, a shorter sampling interval in the beginning of the study period compared to the end of the study makes estimates more precise for the time until infectiousness for group $1 a$ compared to estimates for group $4 a$. Also, in the calculations of the time until onset of infectiousness in the pigs, virus excretion was only considered positive, when Cq values were consistently $<35$, while $\mathrm{Cq}$ values $>35$ or intermittent detection of viral DNA in swabs were regarded as a sign of viral residues being obtained from the environment. This definition is used as it was found that intermittent detection and/or the detection of low levels of viral DNA in the swab samples has corresponded well to the times at which other pigs, in the same stable, were excreting large amounts of virus. Also, using this definition, it was found that virus excretion often coincided with the presence of clinical signs and viremia, supporting the approach used. However, in some cases, low levels of viral DNA in swabs might indicate early virus excretion (e.g. early measurements in the inoculated pigs). Conversely, results indicating low level virus excretion from non-infected pigs (e.g. pigs 7 and 16) may be due to larger amounts of viral residues being obtained from the environment.

In order to propose and implement the most cost-effective control strategies, it is planned, that the data obtained in these studies on infection dynamics in pigs infected with the 
currently circulating ASFV will be incorporated into previously described models for ASFV spread within- and between-herds (Halasa et al., 2016a; Halasa et al., 2016b).

\section{Conflict of interest}

The authors declare no conflict of interest.

\section{Acknowledgements}

We are grateful to laboratory technicians Heidi Elbrink and Hanne Egelund Hansen and to animal caretakers Heidi Lehman, Janni Oxfeldt, Josefine Cecilie Hammer and Marion Baltzer Petersen for their invaluable work during the studies. Also, we thank Karsten Brandt Andersen and Julia Skov (FORCE Technology) for supplying the equipment for air sampling and for their technical assistance.

The studies were funded by the Danish Ministry of Environment and Food and the Technical University of Denmark. 


\section{References}

Bøtner, A., Nielsen, J., Bille-Hansen, V., 1994. Isolation of porcine reproductive and respiratory syndrome (PRRS) virus in a Danish swine herd and experimental infection of pregnant gilts with the virus. Vet. Microbiol. 40, 351-360.

Carrascosa, A.L., Bustos, M.J., de Leon, P., 2011. Methods for growing and titrating African swine fever virus: field and laboratory samples. Curr. Protoc. Cell Biol., chapter 26: unit 26.14.

CEC, 2002, Council Directive 2002/60/EC. Council Directive 2002/60/EC of June 2002 laying down specific provisions for the control of African swine fever and amending Directive 92/199/EEC as regards Teschen disease and African swine fever. Off. J. Eur. Commun. L192 (June), 27-46.

de Carvalho Ferreira, H.C., Weesendorp, E., Quak, S., Stegeman, J.A., Loeffen, W.L.A., 2013. Quantification of airborne African swine fever virus after experimental infection. Vet. Microbiol. 165, 243-251.

Dixon, L.K., Escribano, J., Martins, C., Rock, D.L., Salas, M., Wilkinson, P.J., 2005. Asfarviridae. In Virus Taxonomy, Eighth Report of the ICTV, 135-143

EFSA Panel on Animal Health and Welfare, 2014. Scientific Opinion on African swine fever. EFSA Journal, 12, 3628, 1-77. 
EFSA Panel on Animal Health and Welfare, 2015. Scientific Opinion on African swine fever. EFSA Journal, 13, 4163, 1-92.

The European Commision, 2013. Guidelines on surveillance and control of African swine fever in feral pigs and preventive measures for pig holdings. European Commision working document, 2013.

https://ec.europa.eu/food/sites/food/files/animals/docs/ad_control-measures_asf_wrk-docsanco-2013-7138.pdf

Fernández-Pinero, J., Gallardo, C., Elizalde, M., Robles, A., Gómez, C., Bishop, R., Heath, L., Couacy-Hymann, E., Fasina, F., O., Pelayo, V., Soler, A., Arias, M., 2013. Molecular diagnosis of African swine fever by a new real-time PCR using a universal probe library. Transbound. Emerg. Dis. 60, 48-58.

Gabriel, C., Blome, S., Malogolovkin, A., Parilov, S., Kolbasov, D., Teifke, J.P., Beer, M., 2011. Characterization of African Swine Fever Virus Caucasus Isolate in European Wild Boars. Emerg. Infect. Dis. 17, 2342-2345.

Gallardo, M.C., de la Torre Reoyo, A., Fernández-Pinero, J., Iglesias, I., Munoz, M.J., Arias., M.L., 2015. African swine fever: a global view of the current challenge. Porcine Health Manag. 1, 21. doi:http://dx.doi.org/10.1186/s40813-015-0013-y

Gallardo, C., Soler, A., Nieto, R., Cano, C., Pelayo, V., Sanchez, M.A., Pridotkas, G., Fernandez-Pinero J., Briones, V., Arias, M., 2017. Experimental Infection of Domestic 
Pigs with African Swine Fever Virus Lithuania 2014 Genotype II Field Isolate. Transbound. Emerg. Dis. 64, 300-304.

Gogin, A., Gerasimov, V., Malogolovkin, A., Kolbasov, D., 2013. African swine fever in the North Caucasus region and the Russian Federation in years 2007-2012. Virus Res. 173, 198-203.

Guinat, C., Reis, A.L., Netherton, C.L., Goatley, L., Pfeiffer, D.U., Dixon, L., 2014. Dynamics of African swine fever virus shedding and excretion in domestic pigs infected by intramuscular inoculation and contact transmission. Vet. Res. 45, 93-101.

Halasa, T., Boklund, A., Bøtner, A., Toft, N., Thulke, H-H., 2016a. Simulation of Spread of African Swine Fever, Including the Effects of Residues from Dead Animals. Front. Vet. Sci. 3, 6 .

Halasa, T., Bøtner, A., Mortensen, S., Christensen, H., Toft, N., Boklund, A., 2016b. Simulating the epidemiological and economic effects of an African swine fever epidemic in industrialized swine populations. Vet. Microbiol. 193, 7-16.

Halasa, T., Bøtner, A., Mortensen, S., Christensen, H., Toft, N., Boklund, A., 2016c. Control of African swine fever epidemics in industrialized swine populations. Vet. Microbiol. 197, 142-150. 
Jensen, G.B., Thomsen, L., Veltman, O.R., September 2005. Method, chip and system for collection of biological particles. World International Property Organization patent WO 2005/083391.

King, D.P., Reid, S.M., Hutchings, G.H., Grierson, S.S., Wilkinson, P.J., Dixon, L.K., Bastos, A.D.S., Drew, T.W., 2003. Development of a TaqMan ${ }^{\circledR}$ PCR assay with internal amplification control for the detection of African swine fever virus. J. Virol. Methods. 107, $53-61$.

Mebus, C.A., 1988. African Swine Fever. Adv. Virus Res. 35, 251-269.

Oḷševskis, E., Guberti, V., Seržants, M., Westergaard, J., Gallardo, C., Rodze, I., Depner. K., 2016. African swine fever virus introduction into the EU in 2014: Experience of Latvia. Res. Vet. Sci. 105, 28-30.

Pietschmann, J., Guinat, C., Beer, M., Pronin, V., Tauscher, K., Petrov, A., Keil, G., Blome, S., 2015. Course and transmission characteristics of oral low-dose infection of domestic pigs and European wild boar with a Caucasian African swine fever virus isolate. Arch. Virol. 160, 1657-1667.

Reed. L.J., Muench, H., 1938. A simple method for estimating fifty percent endpoints. Am. J. Hyg. 27, 493-497.

Tignon, M., Gallardo, C., Iscaro, C., Hutet, E., Van der Stede, Y., Kolbasov, D., Mario de Mia, G., Le Potier, M-F., Bishop, R.P., Arias, M., Koenen, F., 2011. Development and 
inter-laboratory validation study of an improved new real-time PCR assay with internal control for detection and laboratory diagnosis of African swine fever virus. J. Virol. Methods. 178, 161-170.

Wardley, R.C., Wilkinson, P.J., 1977. The association of African swine fever virus with blood components of infected pigs. Arch . Virol, 55, 327-334

Wilkinson, P.J., Donaldson, A.I., 1977. Transmission studies with African swine fever virus. The early distribution of virus in pigs infected by airborne virus. J. Comp. Pathol. $87,497-501$.

Woźniakowski, G., Kozak, E., Kowalczyk, A., Łyjak, M., Pomorska-Mól, M., Niemczuk, K., Pejsak, Z., 2016. Current status of African swine fever virus in a population of wild boar in eastern Poland (2014-2015). Arch. Virol. 161, 189-195.

Zakaryan, H., Revilla, Y., 2016. African swine fever virus: current state and future perspectives in vaccine and antiviral research. Vet. Microbiol. 185, 15-19. 


\section{Figure captions}

Figure 1: Illustration of the pens and groups in the two studies, $a$ and $b$. Black dots = inoculated pigs in group $1 a$ (pigs 1-4) and $1 b$ (pigs 23-26) in pen 1 ; white squares $=$ within-pen contact pigs in group $2 a$ (pigs 5-8) and $2 b$ (pigs 27-30) in pen 1; black rhombus $=$ between-pen contact pigs in group $3 a$ (pigs 9-12) and $3 b$ (pigs 31-34) in pen 2; white dots $=$ air-contact pigs in group $4 a$ (pigs 13-16) in pen 3 and white + grey dots $=$ aircontact pigs in group $4 b$ (pigs $35-40)$ in pen 3 ; black + grey squares $=$ control pigs in group $5 a$ (pigs 17-22) in pen 5 and black squares = control pigs in group $5 b$ (pigs 41-44) in pen 5 .

Figure 2: Clinical scores (panel A) and detection of ASFV DNA in EDTA blood by qPCR (panel B) obtained from the inoculated pigs from group $1 a$ (pigs 1-4) and group $1 b$ (pigs 23-26) in pen 1. " $\mathrm{x}$ " indicates the presence of ASFV DNA in nasal swabs, "+" indicates the presence of ASFV DNA in oral swabs and “*” indicates the presence of ASFV DNA in rectal swabs. Shown in non-boldface indicate viral residues from the environment, while shown in boldface indicate viral excretion (definition given in the text).

Figure 3: Clinical scores (panel A) and detection of ASFV DNA in EDTA blood by qPCR (panel B) obtained from the within-pen contact pigs from group $2 a$ (pigs 5-8) and group $2 b$ (pigs 27-30) in pen 1. "x" indicates the presence of ASFV DNA in nasal swabs, "+" indicates the presence of ASFV DNA in oral swabs and "*”" indicates the presence of ASFV DNA in rectal swabs. Shown in non-boldface indicate viral residues from the environment, while shown in boldface indicate viral excretion (definition given in the text). 
NB: Data was only obtained from pig 7 until PID 6, where it was euthanized due to a concurrent gastrointestinal infection.

Figure 4: Clinical scores (panel A) and detection of ASFV DNA in EDTA blood by qPCR (panel B) obtained from the between-pen contact pigs from group $3 a$ (pigs 9-12) and group $3 b$ (pigs 31-34) in pen 2. " $\mathrm{x}$ " indicates the presence of ASFV DNA in nasal swabs, "+" indicates the presence of ASFV DNA in oral swabs and "*” indicates the presence of ASFV DNA in rectal swabs. Shown in non-boldface indicate viral residues from the environment, while shown in boldface indicate viral excretion (definition given in the text).

Figure 5: Clinical scores (panel A) and detection of ASFV DNA in EDTA blood by qPCR (panel B) obtained from the air-contact pigs from group $4 a$ (pigs 13-16) and group $4 b$ (pigs 35-40) in pen 3. " $x$ " indicates the presence of ASFV DNA in nasal swabs, "+" indicates the presence of ASFV DNA in oral swabs and “*” indicates the presence of ASFV DNA in rectal swabs. Shown in non-boldface indicate viral residues from the environment, while shown in boldface indicate viral excretion (definition given in the text)

Figure 6: Air sampling results from studies $a$ (panel A) and $b$ (panel B) shown with the clinical scores in the different groups. In both panels, results presented in blue have been obtained from pigs (dotted lines) and air samplers (symbols) in pen 1. Results presented in green have been obtained from pigs and air samplers in pen 2. Results presented in red have been obtained from pigs and air samplers in pen 3 . In study $a$, air was sampled 1 meter above the pigs $(1 \mathrm{~m})$, just above the pen floor (floor) and 1-2 $\mathrm{cm}$ from the snout of 
diseased pigs (respiratory) over a period of $5 \min$. In study $b$, air was sampled 1 meter above the pigs for $5 \mathrm{~min}$ and 1 hour (5 $\mathrm{min}$ and $60 \mathrm{~min}$ ), respectively. 

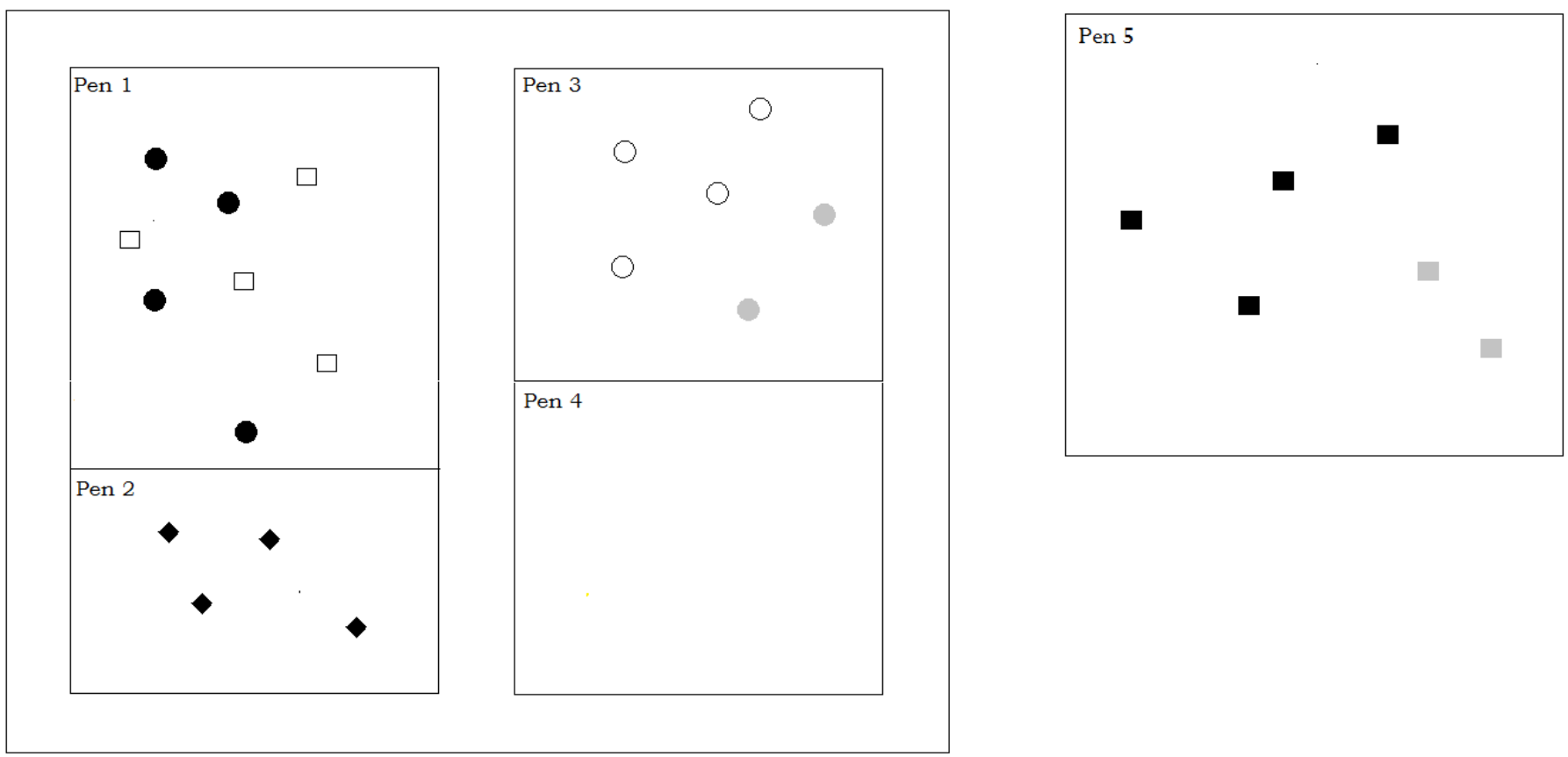

Figure 1 

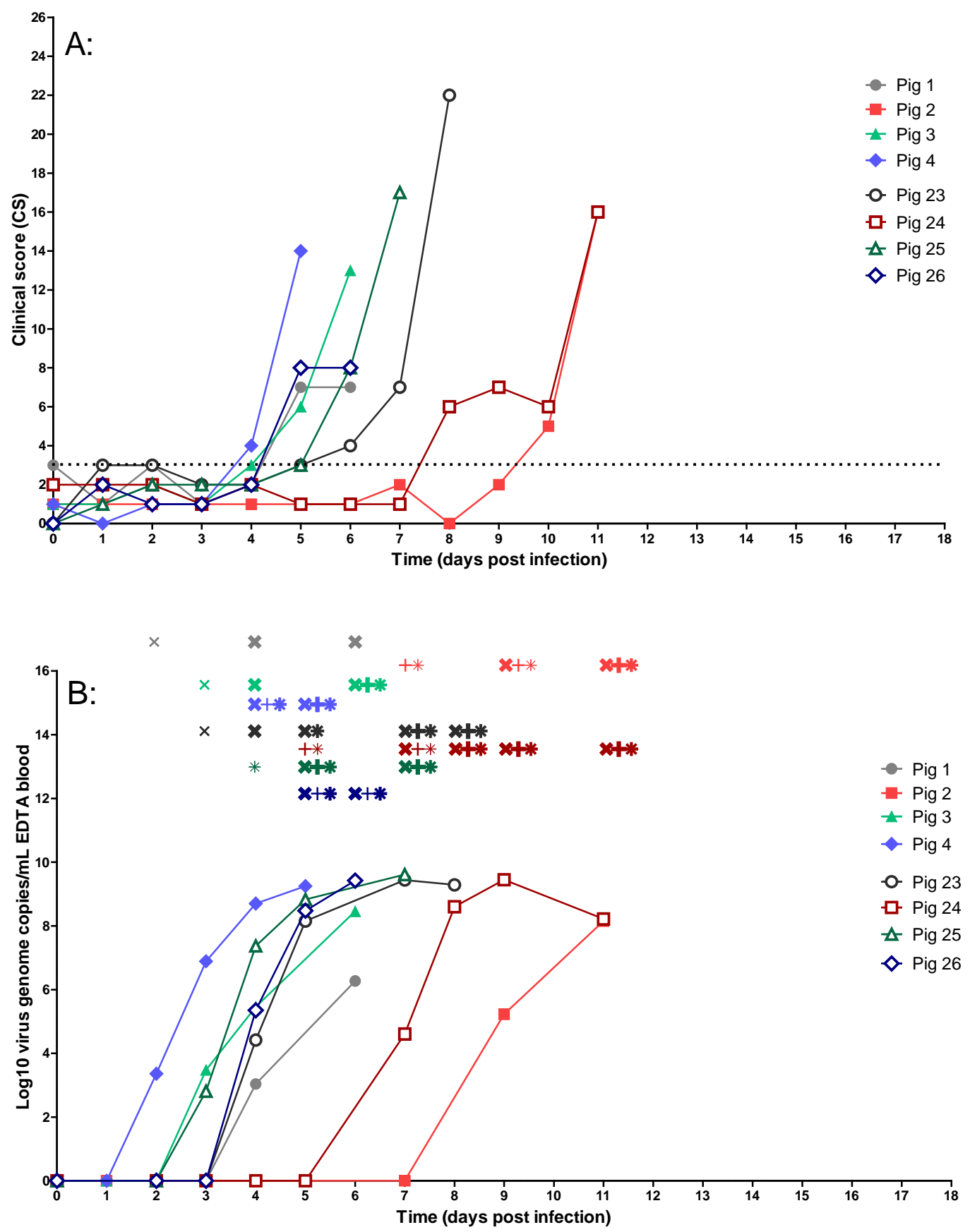

Figure 2 (color should be used in print) 

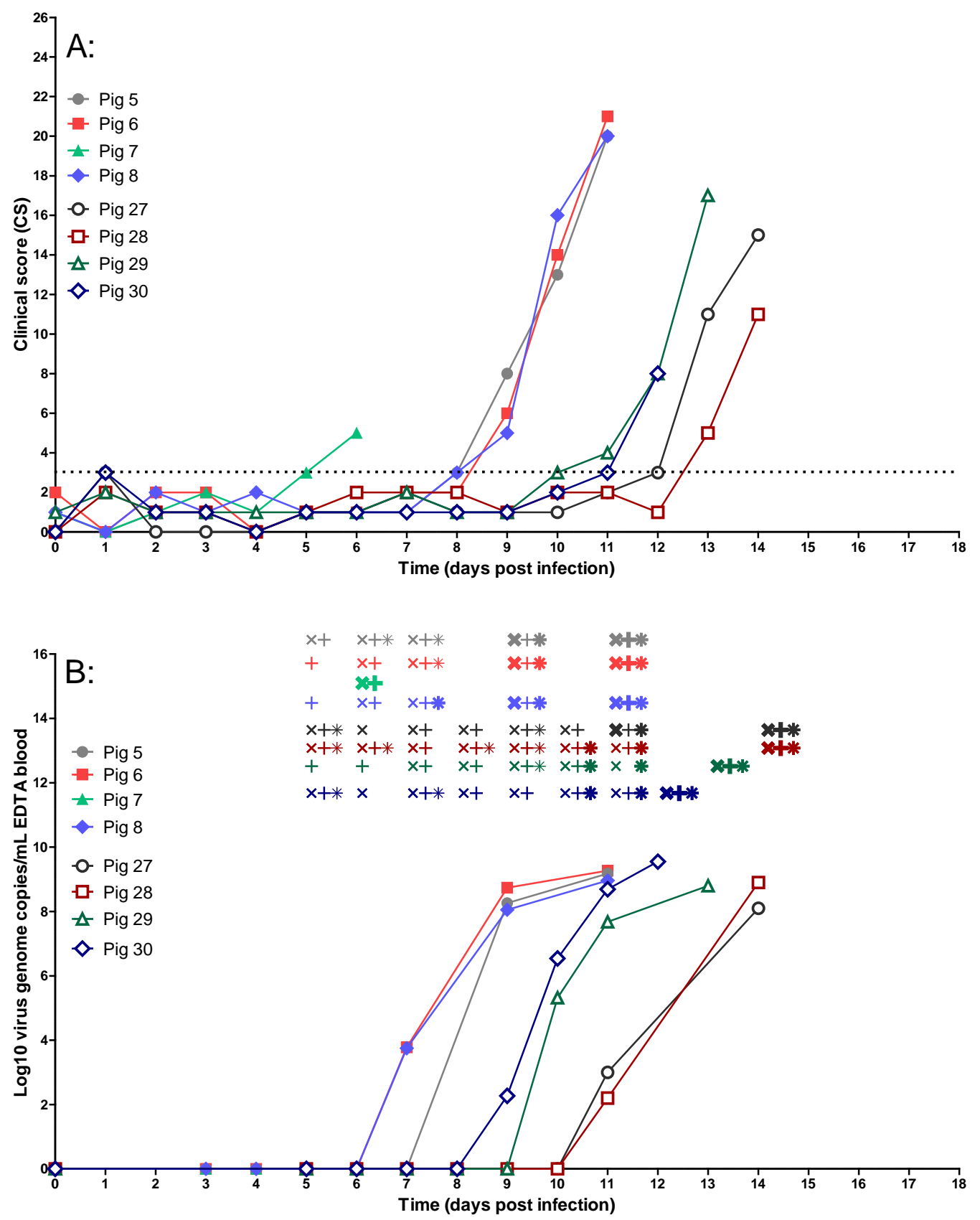

Figure 3 (color should be used in print) 

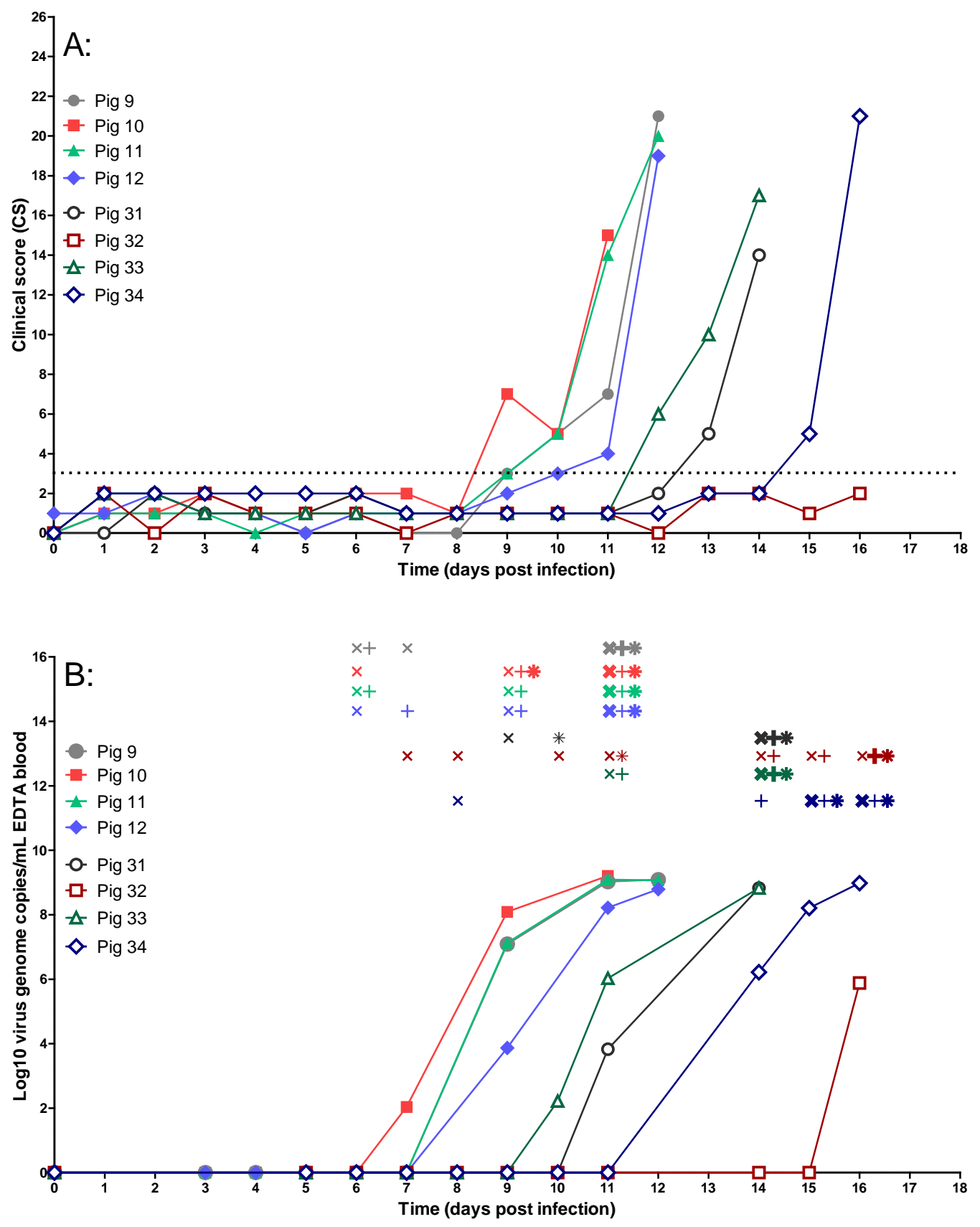

Figure 4 (color should be used in print) 

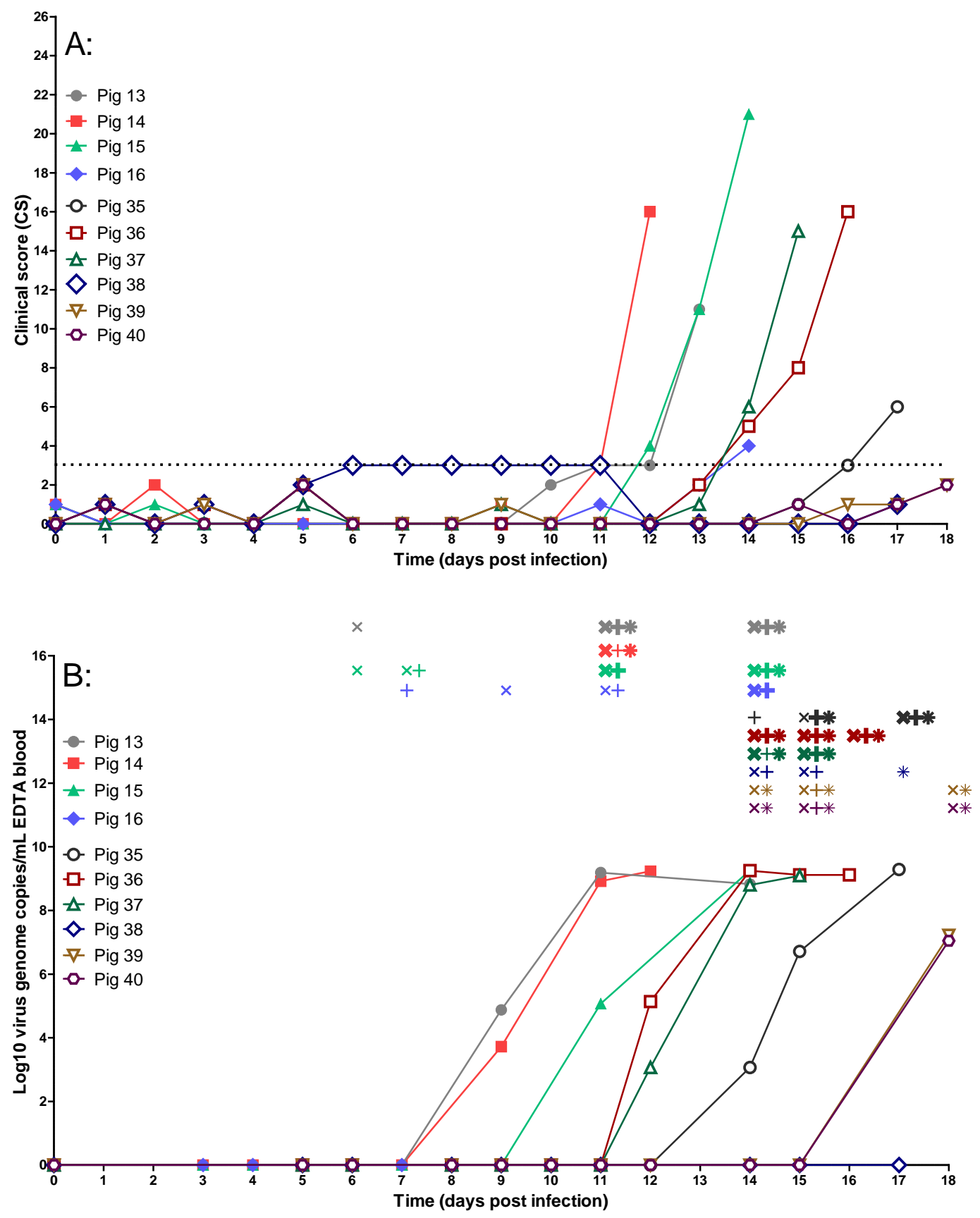

Figure 5 (color should be used in print) 

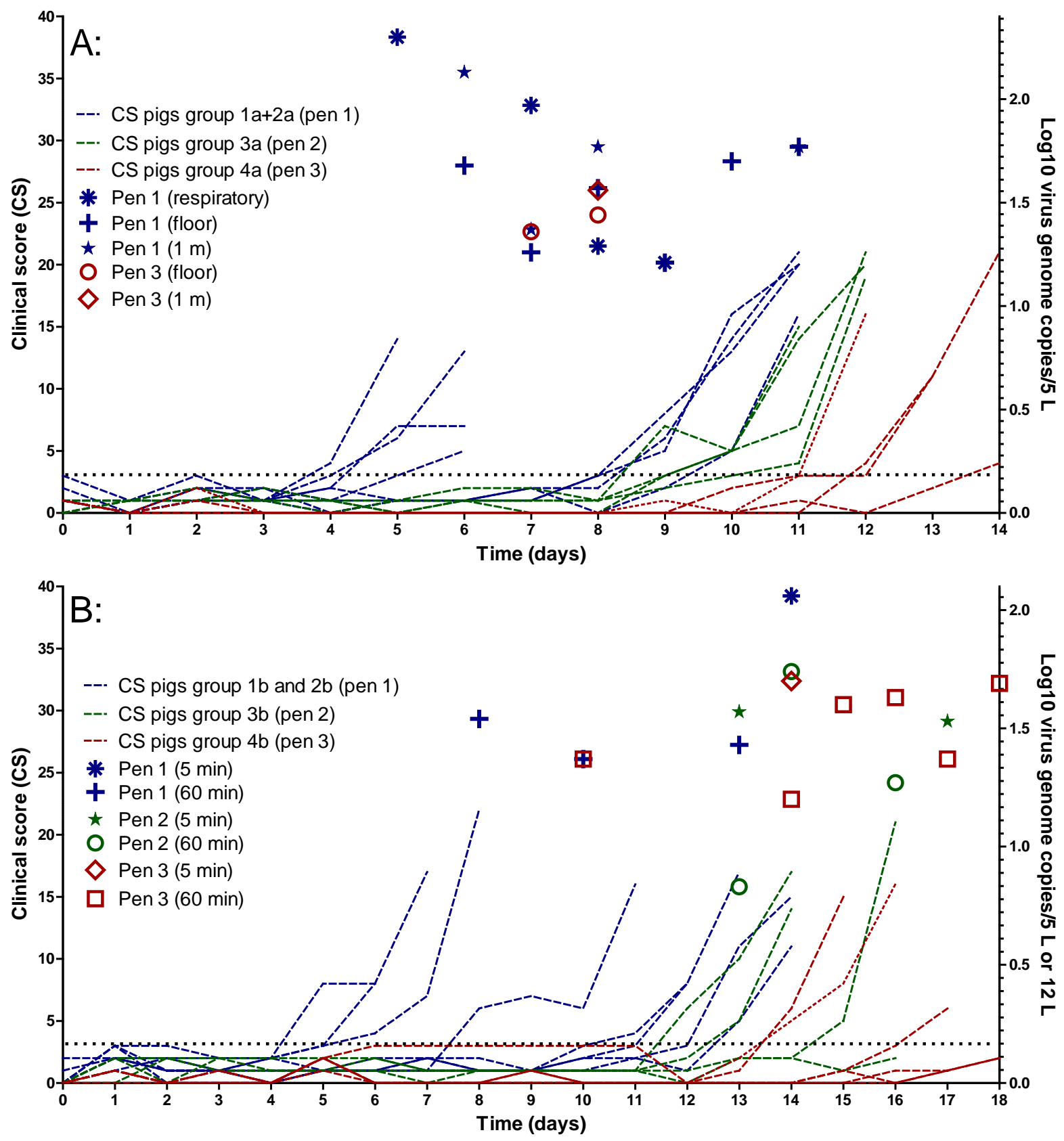

Figure 6 (color should be used in print) 
Table 1: Clinical signs and corresponding clinical scores used for transmission study for ASF:

\begin{tabular}{|c|c|c|}
\hline \multirow[t]{6}{*}{ Temperature } & 0 & $<39.0^{\circ} \mathrm{C}$ \\
\hline & 1 & $39.0-39.5^{\circ} \mathrm{C}$ \\
\hline & 2 & $39.6-40.0^{\circ} \mathrm{C}$ \\
\hline & 3 & $40.1-40.5^{\circ} \mathrm{C}$ \\
\hline & 4 & $40.6-41.0^{\circ} \mathrm{C}$ \\
\hline & 5 & $>41.0^{\circ} \mathrm{C}$ \\
\hline \multirow[t]{5}{*}{ Alertness and recumbency } & 0 & Alert \\
\hline & 1 & Depressed/lethargic \\
\hline & 2 & Only gets up when touched \\
\hline & 4 & Gets up slowly when touched \\
\hline & 6 & Remains recumbent when touched \\
\hline \multirow[t]{4}{*}{ Appetite } & 0 & Normal \\
\hline & 1 & Reduced \\
\hline & 4 & Picking at food \\
\hline & 6 & Does not eat \\
\hline \multirow[t]{4}{*}{ Body condition } & 0 & Normal, full stomach \\
\hline & 1 & Empty stomach, sunken flanks \\
\hline & 2 & Empty stomach, sunken flanks, loss of muscle mass \\
\hline & 3 & Emaciated \\
\hline \multirow[t]{4}{*}{ Skin } & 0 & Normal \\
\hline & 1 & Minimal area of the skin with observed bleeding ( $<10 \%$ of the body) \\
\hline & 2 & Moderate area of the skin with observed bleeding ( $10-25 \%$ of the body) \\
\hline & 3 & Generalized skin bleeding ( $>25 \%$ of the body) \\
\hline \multirow[t]{3}{*}{ Joints } & 0 & No joint swelling \\
\hline & 1 & Swelling \\
\hline & 4 & Severe swelling and lameness \\
\hline \multirow[t]{4}{*}{ Respiration } & 0 & Normal \\
\hline & 1 & Mildly labored \\
\hline & 2 & Labored +/- cough \\
\hline & 3 & Severely labored \\
\hline \multirow[t]{3}{*}{ Eyes } & 0 & Normal \\
\hline & 1 & Small amount of exudate \\
\hline & 2 & Moderate amount of exudate \\
\hline Gastrointestinal and urinary tracts & 0 & No diarrhea \\
\hline
\end{tabular}




$\begin{array}{lll}1 & \text { Mild diarrhea for less than 24 hours } \\ 3 & \text { Diarrhea for more than 24 hours or vomiting } \\ 4 & \text { Bloody diarrhea or blood in urine } \\ \text { Neurology } & 0 & \text { No signs } \\ 3 & \text { Hesitant, unsteady walk, crossing-over of legs is corrected slowly } \\ 4 & \text { Pronounced ataxia } \\ 6 & \text { Paralysis or convulsions }\end{array}$

Table 2: Results of transmission study for ASF, study $a$ : Estimates for the average duration of the incubation period and the latent period for inoculated pigs, and for time until onset of clinical signs (clinical score (CS) above 3 is considered above threshold) and time until onset of infectiousness for contact pig groups.

\begin{tabular}{|c|c|c|c|c|}
\hline & $\begin{array}{l}\text { Inoculated pigs } \\
(1 a)\end{array}$ & $\begin{array}{l}\text { Within-pen contact pigs } \\
(2 a)\end{array}$ & $\begin{array}{l}\text { Between-pen contact pigs } \\
(3 a)\end{array}$ & $\begin{array}{l}\text { Air-contact pigs } \\
(4 a)\end{array}$ \\
\hline & Incubation period (days) & \multicolumn{3}{|c|}{ Time until onset of clinical signs (days) $\S$} \\
\hline & $n=4$ & $n=4$ & $n=4$ & $n=4$ \\
\hline $\mathrm{CS}>3$ & $6.0 \pm 2.7$ & $8.3 \pm 1.5$ & $10.0 \pm 0.8$ & $12.8 \pm 1.0$ \\
\hline Samples & Latent period (days) $\xi$ & \multicolumn{3}{|c|}{ Time until onset of infectiousness (days) $\S$} \\
\hline Sera + & $5.5 \pm 2.7$ & $9.0 \pm 0.0^{*}$ & $9.5 \pm 1.0$ & $12.0 \pm 1.7^{*}$ \\
\hline Sera \# & $5.5 \pm 2.7$ & $9.0 \pm 0.0^{*}$ & $9.5 \pm 1.0$ & $12.0 \pm 1.7^{*}$ \\
\hline EDTA \# & $4.5 \pm 3.1$ & $7.7 \pm 1.2^{*}$ & $8.5 \pm 1.0$ & $9.7 \pm 1.2^{*}$ \\
\hline Nasal swab \# & $5.3 \pm 2.5$ & $8.3 \pm 1.5$ & $11.0 \pm 0.0$ & $11.8 \pm 1.5$ \\
\hline Oral swab \# & $7.3 \pm 3.2^{* *}$ & $9.8 \pm 2.5$ & $11^{* * *}$ & $12.0 \pm 1.7^{* * *}$ \\
\hline Rectal swab \# & $7.0 \pm 3.6^{* * * *}$ & $8.3 \pm 1.2^{* * * *}$ & $10.5 \pm 1.0$ & $12.0 \pm 1.7^{* * * *}$ \\
\hline
\end{tabular}

$\xi$ Average number of days post inoculation ( \pm standard deviation), $\S$ average number of days post exposure ( \pm standard deviation), \# results by qPCR, + results by virus isolation.

* Pigs 7 (group 2a) and 16 (group 4a) did not become viremic, and these pigs are not included in the calculations.

**Viral DNA was not detected in oral swabs obtained from pig 1 (group 1a), and the pig is not included in the calculation. 
***Cq values below 35 were not consistently detected in oral swabs from pigs 10, 11, 12 (group $3 a$ ) and 14 (group $4 a$ ), and these pigs are not included in the calculations. A standard deviation cannot be calculated for group $3 a$.

****Viral DNA was not detected in rectal swabs from pigs 1 (group 1a), 7 (group 2a) and 16 (group 4a), and these pigs are not included in the calculations.

Table 3: Results of transmission study for ASF, study $b$ : Estimates for the average duration of the incubation period and the latent period for inoculated pigs, and for time until onset of clinical signs (clinical score (CS) above 3 is considered above threshold) and time until onset of infectiousness for contact pig groups.

\begin{tabular}{|c|c|c|c|c|}
\hline & $\begin{array}{l}\text { Inoculated pigs } \\
(1 b)\end{array}$ & $\begin{array}{l}\text { Within-pen contact pigs } \\
(2 b)\end{array}$ & $\begin{array}{l}\text { Between-pen contact pigs } \\
(3 b)\end{array}$ & $\begin{array}{l}\text { Air-contact pigs } \\
(4 b)\end{array}$ \\
\hline & Incubation period (days) & \multicolumn{3}{|c|}{ Time until onset of clinical signs (days) $\S$} \\
\hline & $n=4$ & $n=4$ & $n=4$ & $n=6$ \\
\hline $\mathrm{CS}>3$ & $6.3 \pm 1.3$ & $12.3 \pm 1.0$ & $13.3 \pm 1.5^{*}$ & $15.0 \pm 1.7^{*}$ \\
\hline Samples & Latent period (days) $\xi$ & \multicolumn{3}{|c|}{ Time until onset of infectiousness (days) $\S$} \\
\hline Sera + & $4.8 \pm 1.5$ & $12.0 \pm 2.3$ & $13.8 \pm 2.1$ & $15.4 \pm 2.6^{* *}$ \\
\hline Sera \# & $5.3 \pm 1.9$ & $12.0 \pm 2.3$ & $13.8 \pm 2.1$ & $15.4 \pm 2.6^{* *}$ \\
\hline EDTA \# & $4.5 \pm 1.7$ & $10.3 \pm 1.0$ & $12.8 \pm 2.8$ & $14.8 \pm 3.0^{* *}$ \\
\hline Nasal swab \# & $5.3 \pm 1.3$ & $12.5 \pm 1.3$ & $13.3 \pm 2.1^{* * *}$ & $15.0 \pm 1.7^{* * *}$ \\
\hline Oral swab \# & $6.7 \pm 1.5^{* * * *}$ & $13.3 \pm 1.0$ & $15.0 \pm 1.2$ & $14.7 \pm 0.6^{* * * *}$ \\
\hline Rectal swab \# & $5.8 \pm 1.5$ & $10.3 \pm 0.5$ & $14.8 \pm 1.0$ & $14.3 \pm 0.6^{* * * * *}$ \\
\hline
\end{tabular}

$\xi$ Average number of days post inoculation ( \pm standard deviation), $\S$ average number of days post exposure ( \pm standard deviation), \# results by qPCR, + results by virus isolation. *Pigs 32 (group 3b), 38, 39 and 40 (group 4b) did not reach a clinical score above 3, and these pigs are not included in the calculation.

**Pig 38 (group 4b) did not become viremic and this pig is not included in the calculation. 
***Cq values below 35 were not consistently detected in nasal swabs from pigs 32 (group 3b), 38, 39 and 40 (group 4b) and these pigs are not included in the calculations.

$* * * * \mathrm{Cq}$ values below 35 were not consistently detected in oral swabs from pigs 26 (group $1 b$ ), 38, 39 and 40 (group 4b) and these pigs are not included in the calculations. $* * * * * \mathrm{Cq}$ values below 35 were not consistently detected in rectal swabs from pigs 38,39 and 40 (group $4 b$ ) and these pigs were not included in the calculation. 